\title{
Framing public health in Romanian media between 1918 and 1945
}

\section{DOI: http://doi.org/10.26758/9.1.6}

Valentina MARINESCU

Faculty of Sociology and Social Work, Bucharest, Romania

Address correspondence to: Valentina Marinescu, Faculty of Sociology and Social Work, 9, Schitu Magureanu Bd, Bucharest, Romania, Ph.: +40-720-024-813;

E-mail: vmarinescu9@yahoo.com

\begin{abstract}
Objectives. The aim of the present paper was to present media coverage of public health in Romanian printed press between 1918 and 1945.

Material and methods. A quantitative content analysis was made on a sample of 81 articles published in Romanian reviews and magazines between 1918 and 1945. Descriptive statistics was used in the analysis of the results.

Results. The findings can be summarized as follows: 1). There was a small number of sources related to medical system and public health cited in the articles but they were of high quality (doctors, ministers, researchers and professors at the faculty of medicine); 2). The main type of event related to medicine and public health covered by Romanian media in that period of time was routine event (and not accident or/and scandal); 3). The journalists had adopted the role of educators about the medical system and public health.

Conclusions. The basic conclusion of the study is that the media from 1918-1945 had covered the public health and medicine in a different manner that it is made today, by putting a greater stress on the quality of information regarding health and medicine, stressing the objectivity of the scientific evidences and quoting experts from the domain in direct reference to the topics.
\end{abstract}

Keywords: health communication, media framing of public health, Romanian public health, public awareness of health and illness.

\section{Introduction}

In present days, as the existing literature shows (McCombs, 2004, p. 7-13), the news production is influenced by organizational and professional variables (professional norms, individual and professional values). Whether individually or as part of a group, professional values adapted to the requirements of society and ideology can be found in the institutional, occupational and cultural practices composing the media. The media content no longer appears as an "isolated", but as a product deeply rooted into the social world, being organizationally determined. Occupational routines of journalists relate to broader ideological needs. The media is a body of work relevant for understanding the nature and the importance of content effects on people and society (knowing the media, content, its effects on the audience can be predicted). McCombs (2004, p. 71-76) widely considered the problematic role of the media in creating public interest topics. According to his analysis, the most important aspect of the role of public agenda for the media is to influence public opinion, and his argument is based on several elements. First, the themes that capture people attention are known through newspapers, not through personal experience. Secondly, the news functions as a signal, alerting people on the latest developments in the near or more distant environment. Third, journalistic content, resulting 
from specific rules of selection and packaging, directs public attention and influences the perceptions of individuals (McCombs, 2004, p. 75).

If today we have all the tools necessary to identify the above-mentioned elements through which the print media provides a picture of reality, what was the situation in the past? In addressing this question we intend to return in time in order to see how news production and journalistic practices were embedded in media products. For that, we have chosen the period 1918-1945 in Romania and we have been interested to trace the media's perspectives from which the issue of public health was then addressed in media - the newspapers, reviews, and magazines.

The general research question we address in this paper was: "What was the media coverage of public health in Romanian printed press between 1918 and 1945?"

The specific objectives of this paper were the followings:

RO1. To present the journalistic procedures used in articles covering the topics of public health published in Romanian written press in the period 1918-1945;

$\mathrm{RO} 2$. To identify the frames used in presenting the topics related to the medical system and public health in Romanian printed press in the inter-war period.

\section{The historical context of Romanian medicine and public health between 1918 and 1945}

After the reunification of 1918 and the establishment of "Great Romania", the first Romanian Law regarding public health was adopted in 1921 and it had established the basis of the unification for the entire medical system in Romania. Between 1918 and 1921 Transylvania, Bukovina and Bessarabia (the new provinces annexed to the Romanian Kingdom in 1918) remained under the same public health inspectorates inherited from the former Austro-Hungarian Empire and those had functioned according to the Austro-Hungarian normative acts.

The new Sanitary Law from 1921 had allowed the unitary management of various medical structures from the new provinces and the Old Kingdom. In the same year (1921), through the amendment to the Sanitary Law, the Ministry of the Interior was put in charge with the administration of hospitals, hospices, asylums and all medical facilities from the so-called "Allied Territories". One year later, a change of the central medical structures took place through the setting up of the Ministry of Public Health, Labor and Social Affairs. In 1930, the Law on Health and Prevention was the first unique law of health for entire Romania and it included most of the progressive ideas on social hygiene specific to the medical school from Cluj (especially those originated from Iuliu Moldovan). The law had stated the fact that new medical principles and practices were parts of the Romanian state's plan to implement the specific objectives aiming at the protection of Romanian population's health.

The Romanian health system established in 1921 remained in force until 1948 when, as the results of passing a new Constitution voted on April 13, 1948, and the Law of Nationalization Law (11 November 1948), all state and privately-owned hospitals and clinics became state property. Only in 1978, the "Health Insurance Act for Romanians" was adopted and it was the first law after 1948 that regulated the Romanian medical system after almost half of a century.

Between 1918 and 1940, the Ministry of Health had passed through a series of administrative changes in order to become an independent institution (Setlacec, 1998, p. 14): "In 1923 the Ministry of Public Health, Labor and Social Welfare was divided into different institutions. On the one hand, the Ministry of Public Health and Social Protection was set up and, on the other, the Ministry of Labor, Social Insurance and Cooperation was organized. In 1926, the two ministries were merged, and until 1938 they had functioned as a unitary structure. In 1938, the Ministry of Health was once again set up as an independent entity". 
The law adopted in 1923 had led to administrative changes, especially regarding the activity of physicians, their number increasing at the level of Romanian villages. The issue of hospitals and that of the entire medical system's efficiency have become top priorities in the inter-war period, and they were assessed by one Romanian health minister as being "at least as important as national defense" (Setlacec, 1998). All these changes had led to the development in the medical practices and institution, especially in the field of surgery and public health.

Other medical institutions set up were the so-called "Eforia of the Civil Hospitals in Bucharest" which had attempted to provide free medical services for the population (within the existing financial resources) and had managed a number of clinics and hospitals throughout the country. Its activity was not interrupted during the Second World War, and the financing of those institutions had been diverse (from donations to shares or loans) securing their ability to provide free access to people at health-related services, until near the end of the war when they were obliged to introduce hospitalization fees. Other institutions set up after 1930 were the "Brâncoveanu Settlements", which were made up by merging the existing Brâncovenesc Hospital with Domniţa Bălaşa Foundation.

At the end of the First World War, the Central Social Insurance House was transformed into an "autonomous body" which had meant the development of compulsory health insurance and its subsequent changes. After 1933 the resources of Central Social Insurance House had increased, and a series of non-binding insurance for health enters into force for the general Romanians. Other medical institutions that had been functioning in the same period of time include the Army's Sanitary Service (which was set up to assist the victims of the war), the "National Office of Invalids, Orphans and War Widows", medical services provided for the employees of the Romanian Railway Network, the ambulance system and the Emergency Hospital which were managed by the Red Cross.

The physicians from this period were also well-known scientists, known not only in Romania but also abroad. Their total of doctors in Romania during the inter-war period was around 8.000, but they were mainly working in big cities, few of them choosing to settle up their cabinets in rural areas that remained disadvantaged as regards health-related services. The scientific medicine was in a direct and open conflict with charlatanism, which also had reached impressive odds in those years, witchcraft and occultism being among the favorite methods of "amelioration" of medical conditions for many Romanians (Setlacec, 1998).

A general perspective on the state of the medical system at the beginning of the twentieth century allows us to notice the existence of a cultural boundary between doctors and the average men. In spite of the hard struggle that the medical staff wore to maintain a balance between the disordered lives of their citizens, their morals, and their access to the existing medical facilities, most of the time the medical staffs' efforts to educate Romanians were somehow "a lost battle".

Unfortunately, the rural population was still deprived in a great part of free access to health-related services, the number of insured Romanians living in villages remaining very small (Setlacec, 1998, p. 16): "The reasons for this situation were different: intermittent character of work in the villages, not so clear separations among land-owning, low incomes that did not allow for health-related contributions, the annual variation for rural household incomes, the difficulties for providing mandatory and prompt medical assistance for a geographically dispersed population, the small number of doctors who had set up their cabinets in rural areas".

The ways the peasants managed to avoid the "threat" of the medical system's development reach were quite unusual, even for trained doctors. Apart from the clear social class difference between peasants and doctors and the precarious economic situation both social groups faced one could add the high level of misinformation existing at the level of disadvantaged class, the rural population. The indifference of the rural population with regards to curative and preventive medicine was high (Bărbulescu, 2010, p. 7): "Medicalization can only be 
understood through the grid of the opposition between the dominant culture and the subaltern culture, and with the birth of modernity culture the peasantry becomes and remains in a subordinate position through the entire period of time."

In fact, all the peasants' efforts to avoid modern medicine were the result of their fears towards modern life. The changes brought about by the evolution of the healthcare system, possibly the pressure exerted by the doctors, combined with the lack of adequate basic education have led peasants to seek their own "remedies" rooted into folklore and magical thinking (Bărbulescu, 2010, p. 7): "Healers in the villages have always existed in pre-industrial peasant societies, and Romanian rural communities were not exceptions. Any peasant society has selfregulated the disease-healing-death relationship. Before the advent, if modern doctors and medicine, [...] the peasant communities had solved the problems of illness and healing by resorting to persons specializing in certain diseases, clearly defined by a so-called nosology, specific for a peasant medical culture".

Another important aspect of the peasants' assessments of disease and healing are spiritual beliefs. Divinity played the leading role in influencing the decision-making of the patients in this period of time. On that basis a number of practitioners existed the entire modern and contemporary period within the rural communities (Bărbulescu, 2015, p. 238): "There are also the "orthopedic specialists", peasant occultists, and finally, a lot of healers specialized in various diseases, such as Marin Catana, who cure rabies, or Stoian Buruiana, who cure madness. Along with them come different specialists of remorse against magical aggression: monks, priests, and wizards."

The reason for which all those healers were assessed by peasants as being "omnipotent" was the fact that, according to the (pre-modern) peasants' representations, disease was not a disorder of the bodily mechanism (humoral or physiological), but was always "either a divine punishment or the result of magic agents' actions" (Bărbulescu, 2015, p. 238): "The belief that man has to pass through physical sufferings following deviations from religious canons was deeply imprinted in the mentality of the peasants, and any way of science to destroy this dogma was viewed with hostility by them."

If this was the image of the Romanian society between 1918 and 1945 our interest was directed towards the ways in which Romanian media of that period of time covered the issues of public health. For that, the following section will deal with some concepts of the sociology of news which could be of help in our approach.

\section{Elements of the sociology of news}

In his seminal work about media coverage and journalistic practices, Entman had defined frames as a process which implies (Entman and Rojecki, 1993, p. 52): "[To frame is] to select some aspects of perceived reality and make them more salient in a communicating text, in such a way as to promote a particular problem definition, causal interpretation, moral evaluation, and/or treatment recommendation."

Referring to the research tradition of framing theory, D'Angelo (2002) had identified three central paradigms of it: the constructionist perspective, the critical approach and the researches, which used the cognitive perspective. If the constructive approach focused on the interaction between journalists and frames (Shah et al., 2010), the critical paradigm considered that frames are essentially social and that they varied from the social and cultural points of view (Ettema and Peer, 1996; Gamson and Modigliani, 1989). In the meantime, the cognitive perspective assessed that framing effects were the result of the negotiation processes existing between the audience's direct knowledge of an event and the media frames (Baresch, Hsu and Reese, 2012). 
In the existing literature, one can also identify several classifications of frames. Thus Iyengar (1990) distinguished between two main types of media frames: episodic frames - those cover the news in personal terms, providing specific cases, individual accounts, and personal experiences; and, on the other hand, thematic frames - those offer relevant information for wider analysis, outlining the general trends around the phenomenon or event presented through the use of statistics or data from various sources. De Vreese and Boomgaarden (2003) also had identified two different types of media frames: issue-specific frames - which are used for specific media events, and they allow detailed and in-depth analysis for certain events (but this analysis is difficult to generalize in the construction of some theories); and generic frames - these refer to different topics in various contexts and timeframes, allowing generalizations of results. In his analysis, Scheufele (2002) presented two different types of frames: formal-abstract frames (which clearly refer to a particular event or episode covered in the media) and content-related frames (they can transmit meanings centered on more global issues).

\section{Material and methods}

The way the analysis of media frames is conducted is different in the specialized literature, as shown by Semetko and Valkenburg (2000). Therefore, the inductive analysis of the frames analyses small article samples, building on some very general analysis directions, in order to extract possible frames of news coverage. On the other hand, the deductive approach of the frames uses large samples, defines particular frames and counts their appearances within articles in order to highlight the differences that exist among different types of mass media content.

In our study, we used an inductive approach for the frame analysis. The advantage of this perspective stands in its capacity to capture the diversity of frames which can be identified in the sample of the analyzed article. At the same time, we were interested in identifying the frames at a double level - both as prime definers of the situation and as the entire analyzed corpus (Ferree et al., 2002).

As the main method for research we have used quantitative content analysis, a method which is systematic and objective in analyzing media texts (Chelcea, 2001).

The sample of the present analysis was made of 81 randomly chosen articles dealing with the issue of public health which were identified in nine Romanian reviews and magazines from 1918-1945.

The magazines were consulted online on the "Digital Library of Bucharest" and they were presented in the Table 1 from bellow:

Table 1. Sample analysed (articles from reviews and magasines)

\begin{tabular}{|l|c|}
\hline \multicolumn{1}{|c|}{ Name of the review or magazine } & Number of articles \\
\hline "Albina" ["The Bee"] & 15 \\
\hline "Boabe de grâu" ["Grains of wheat"] & 9 \\
\hline "Epoca" ["The epoch/era"] & 9 \\
\hline "Pagini populare" ["Popular pages"] & 10 \\
\hline "Medicina populară" ["People's Medicine"] & 9 \\
\hline $\begin{array}{l}\text { "Memoriile secţiunii ştiinţifice - Secţiunea Medicală ["The } \\
\text { memories of the scientific section- Medical section"] }\end{array}$ & 10 \\
\hline "Monitorul Oficial" ["The Official Monitor"] & 9 \\
\hline "Sociologie românească" ["Romanian Sociology"] & \\
\hline
\end{tabular}

The grid for content analysis had been devised alongside two main axes. The first dimension, which had focused on drafting issues, author identity and media coverage, included 
the items related to the type of article; article's size; its position within the review's or magazine's page; the impact of the title on the reader; the identity of the author; the attitude of the author towards the topic and the style of coverage. On the other hand, the second dimension had dealt with the assessment of the content of articles and consisted of the following items: the status of the topic in the general review's or magazine's issue; the reference made to Romania or to other countries; the medical specialty covered in the article; the type of reference to medical issues and general framework of the article within the existing agenda of the period of time considered.

The period of time in which all data were collected was November 2018-January 2019. The statistical package used for data analysis was SPSS 11.5 and the article presents mainly descriptive statistics of data.

\section{Results}

According to the data set, the image of public health in Romanian magazines was built mainly by experts in medicine and health who authored the majority of articles enclosed in the analysis - 43 articles from the total $(53.75 \%)$. From a qualitative point of view, if someone is analyzing those articles in a qualitative way, the fact that an expert opinion is expressed about health in half of the sample could be assessed as being relevant for the reader and the rest of the society (Beciu, 2011). Those results were supported also by the fact that we found only one article $(1.25 \%)$ which was simple news about public health.

Table 2. Type of article about public health

\begin{tabular}{|l|c|c|}
\hline & $\mathrm{N}$ & Percent (\%) \\
\hline Article written by an expert & 43 & 53.75 \\
\hline News & 1 & 1.25 \\
\hline Law referring the medical system and/or health & 11 & 13.75 \\
\hline Advertising & 11 & 13.75 \\
\hline Simple article & 15 & 17.50 \\
\hline
\end{tabular}

An interesting aspect worth mentioning is the equality which was recorded between articles making advertising for healthcare or medical services and those outlining the legislative framework of the public health system, namely 11 articles $(13.75 \%)$ in each case. This showed us "the double-face" of Romanian reviews and magazines' coverage of the public health during that period of time: on the one hand, it was presented as advertising to medical products and institutions and, on the other, the stress was put on the role of media as formal educators about the medical system through the use of citations from laws and official documents in the articles. The coverage of public health in a simple, direct way was recorded in the case of 15 articles $(17.50 \%)$ those providing in general an objective approach to the topic. The articles which could be assessed as objective consisted mainly of recommendations for improving the medical conditions, pieces of advice to avoid common diseases, etc. This suggested the fact that, to a certain degree, the coverage of public health remained a specialized one even if the article is not written by an expert in the field but by a journalist who collected the medical information and packed it according to the norms of her profession.

Table 3. The article was published together with a photo

\begin{tabular}{|l|c|c|}
\hline No photo was published together with the article (only text) & N & Percent (\%) \\
\hline $\begin{array}{l}\text { A photo was published together with the text (the article was } \\
\text { published together with a photo) }\end{array}$ & 23 & 66.25 \\
\hline
\end{tabular}




\begin{tabular}{|l|c|c|}
\hline $\begin{array}{l}\text { Only a photo had took the place of the text (it was an advertising } \\
\text { for a medical product) }\end{array}$ & 5 & Percent (\%) \\
\hline
\end{tabular}

A total of 53 articles analyzed (66.25\%) present the subject of health without using any image, 23 of them $(28.75 \%)$ covered the topic and publish also a photo together with the text and only 5 articles $(5 \%)$ had used only a simple image which was not accompanied by a text, the latter case being exclusively advertisements promoting either medical institutions or various medical practices or services. We can notice also the fact that the majority of articles published without images were written by experts who had been used a specialized language that is explicit enough to clearly convey the essential health ideas. This approach in Romanian printed press of the period could be assessed as stressing the fact that the reader's attention to the topic should not be visually attracted by the images but only by the quality of information from the articles. Not even in the case of the news about health and medical system the articles there was no image published together with the text.

Even in the case of the articles which were published together with an image (23 articles, meaning $28.75 \%$ of the entire sample) the photos and drawings were mainly medical objects or products. The journalists had used them only them when the content of articles had made reference to treatments or natural remedies, to present a scientist from the medical field or to present and to promote medical services or institutions.

Table 4. The length of the article

\begin{tabular}{|l|c|c|}
\hline & $\mathrm{N}$ & Percent (\%) \\
\hline One page & 31 & 38.75 \\
\hline More than a page & 46 & 57.50 \\
\hline Less than a page & 4 & 3.75 \\
\hline
\end{tabular}

From the entire sample enclosed in the analysis, a total of 46 articles $(57.5 \%)$ had covered the issue of health in more than one page. This situation was recorded mainly in the case of scientific reviews magazines, which obviously had given the subject a particular importance, treating it even in exclusivity.

The issues related to public health were covered in 31 articles $(38.75 \%)$ of one-page length, those being mainly simple articles and news. Articles whose main themes were medical recommendations or guidelines provided to the reader in order to identify his/her medical conditions by presenting diseases' symptoms had chosen to provide this information in a concise, objective manner which had fit into a page from the publication.

We also identified four (4) articles that covered the topics related to public health in less than one page (3.75\%). Those articles were mainly advertisings to medical products and/or institutions.

Table 5. Place of the article within the page of the review or magazine

\begin{tabular}{|l|c|c|}
\hline & $\mathrm{N}$ & Percent (\%) \\
\hline Right up of the page & 10 & 12.50 \\
\hline Left up of the page & 14 & 17.50 \\
\hline Right down of the page & 7 & 8.75 \\
\hline Left down of the page & 16 & 21.25 \\
\hline In the middle of the page & 34 & 42 \\
\hline
\end{tabular}


The positioning of the article on the page does not necessarily represent a tool for measuring its importance as long as it is seated in the right-down, left-to-bottom, but as it occupies the middle of the page one could consider it as being relevant for the general political economy of the publication.

As our data showed, 34 articles ( $42 \%$ of the entire sample) were placed in the middle of the page, which meant the fact that the topic was considered important by the journalists. For the rest of the sample (47 articles - 56\%) our data showed that they were positioned as follows: in the bottom left side of the page - 16 articles (21.25\%), in the top/upper-left side of the page - 14 articles $(17.5 \%)$, in the top/upper-right side of the page - $10(12.5 \%)$, and in the bottom right of the page - 7 articles $(8.75 \%)$.

The placement of an article on the front page is an element which points out the relevance of the topic covered for the editorial agenda of the publication. In the case of our data, only seven (7) articles (7.5\%) were published on the front page of the review or magazine. It is worth to notice that those were strictly specialized publications which were focused entirely on health and medicine. The majority of articles (64, that is $77.5 \%$ of the sample) had published the articles on another pages that the first or last ones. Also, 10 articles $(12.5 \%)$ had been published on the last page, but those were mainly advertisements at medical facilities and/or institutions or drugs.

As regards the identity of journalists who wrote the articles our data showed that 30 articles (37.5\%) had male authors, 39 articles (48.75\%) had female authors, and, in the case of 12 articles $(13.75 \%)$, there was no specification about the gender of the journalist.

Table 6. Identity of the article's authors

\begin{tabular}{|l|c|c|}
\hline & N & Percent (\%) \\
\hline A single author & 60 & 75 \\
\hline Many authors & 9 & 11.25 \\
\hline Not specified (Unknown author) & 12 & 13.75 \\
\hline
\end{tabular}

According to our set of data, the majority of articles - $60(75 \%)$ - were written by a single author, $9(11.25 \%)$ of them were written by several authors, and, in the case of 12 articles $(13.75 \%)$, the number of their authors remained unspecified.

As regards the place of the articles covering public health issues with the general "economy of the publication" our data showed that 50 of them $(62.5 \%)$ have this theme as a secondary one. Public health was the main theme only in 19 articles $(23.75 \%)$ and here again was the case of those magazines which were specialized in health and medicine. Also, in the case of 11 articles (13.75\%), public health was only accidentally mentioned - this was the case of advertisings, announcements or of the short articles with medical recommendations for different diseases.

When public health issues are related to a certain place our analysis showed that 64 articles $(78.75 \%)$ mentioned only Romania (Bucharest, Cluj, Iasi and some non-specified rural areas), 7 articles $(8.75 \%$ ) had made reference both to Romania and to other regions of the world (Europe or America), and 10 articles (12.5\%) made a clear reference only to Europe.

The most common type of medical specialty covered in the articles analyzed was general medicine - 24 articles $(30 \%)$ - followed by dentistry, internal medicine and genetic medicine - each of them being covered in 6 articles (7.5\%). We notice that all articles covering specialties of the medical domain have been authored mainly by experts and not by journalists.

Another sub-set of articles - 7 (8.75\%) - have made references to medical institutions such as health care facilities, pharmacies or medical offices. Typically, these articles were advertising and promoting the services offered by those institutions. 
At the same time, our data had shown that only one (1) article $(1.25 \%)$ had made reference to health-related issue from the point of view of naturalist remedies, in this case the general topic was the beauty treatments for women.

The lifestyle and the role of medical advice related to diets for the population were not stressed within the articles analyzed. According to our set of data, only 4 articles (5\%) referring to the health sector had covered those issues. As compared with nowadays media this small percentage could point to the low interest put on a scientific-guided nutrition by the written press between 1918 and 1945. Another domain which is different in comparison with the present-day media is the way in which "gynecology" and all its branches (gynecological diseases, contraceptive methods, and sexually transmitted diseases) were covered by the articles we analyzed. Only one (1) article (1\%) addresses this domain, and it did not refer to the contraceptive methods or sexually transmitted diseases, but to so-called "female" medical issues related to health and illness.

Not all articles from the sample had made a clear reference to a particular specialization of medicine, and 21 articles $(26.25 \%)$ had covered health-related issues at a very general level, focusing on health in general or they presented only the situation of the Romanian medical system as a whole. Another sub-set of 14 articles (17.5\%) had presented the results of medical research, the evolution of medicine as science or some influent scientists of the period. Three (3) articles $(3.75 \%)$ had addressed general health issues, describing various diseases, warning about the symptoms of various health conditions, and offering treatment suggestions.

In 14 articles $(17.5 \%)$ the health system is presented from the legal point of view, the stress being put on the laws regulating public health during that period of time, the public health initiatives and state's public policies related to public health, the norms and regulations which had been in function within the medical field. This was the case with the articles published mainly in "The Official Monitor", through which the Romanian readers could have had access to the legislative changes of the medical system.

Apart from that, 22 articles $(27.5 \%)$ had reconstructed the image of public health and medicine through the appeal at doctrines, ideas, and theories about the medical system, using "health" versus "illness" as generic, axiological terms. Ten (10) articles (12.5\%) had covered the issues of public health by offering descriptions of the scientific researches, making reference at the evolution of medical practices and presenting outstanding Romanian personalities from medical sciences.

Our analysis also stressed the fact that three (3) articles (3.7\%) had connected the issue of public health to the distribution of anatomical human features according to geographic areas. In 15 articles (18.75\%) the stress was put on public health issues from the perspective of causes and solution for various diseases in different regions of the country. In the case of 5 articles $(6.25 \%)$ the topic of public health was connected to the presentation of some treatments, those articles having mainly a descriptive character, stressing symptoms (e.g. what they called "alarm signals" regarding the existence and manifestations) of various diseases.

A separate category was that of "Medical Guidance" which appeared in the case of 10 articles $(12.5 \%)$. This category contained the specialized information about certain diseases, their treatments and ways of preventing them provided by the journalists and/or the medical experts. Eleven (11) articles (13.75\%) were advertising articles, which promoted certain services, medical institutions or even practitioners in some specialized medical domains. Scientific articles had made around a quarter of the sample - 18 (22.5\%) - and they were devoted exclusively to the medical field covering all areas, the evolution of medical scientific researches and the presentation of medical experts.

The events related to public health were actually built as a necessity of informing the readers about the evolution and dynamics of the medical sector, and this was the case with only two (2) articles (2.5\%) for the entire sample. 37 articles $(46.25 \%)$ had presented an event which 
was related to the personal experience of the patient, the discoveries from medical research, the legislative changes or the actions of the local government related to health system:

Table 7. Type of event covered by the media

\begin{tabular}{|l|c|c|}
\hline & $\mathrm{N}$ & Percent (\%) \\
\hline Medical discoveries & 46 & 58.30 \\
\hline New laws and regulations regarding public health and medicine & 26 & 33.30 \\
\hline Personal experience of a patient & 7 & 8.33 \\
\hline Actions of local administration related to health and medical system & 2 & 2.77 \\
\hline
\end{tabular}

In the case of 20 articles $(23.75 \%)$, the health-related event was clearly presented as being connected to the medical domain, while in the case of 61 articles $(76.25 \%)$ this connection was not evident (that is, it was only implicitly stated).

71 articles $(88.75 \%)$ did not refer to any person from the medical field, in 2 articles $(2.5 \%)$ there were presented cases involving only adults aged 35-60 years, in the case of 2 articles $(2.5 \%)$ the reference was made to children aged 5 to 11 and 5 articles $(6.25 \%)$ covered youths aged between 11 and 35 years.

Only in the case of 15 articles $(18.75 \%)$ a person or more were cited as they had stated something about medicine or public health. The persons quoted were doctors - in 10 articles $(12.5 \%)$, patients - in 2 articles $(2.5 \%)$, researchers, ministers, and professors at the faculties of medicine - each quoted in one (1) article (1.25\%).

In 37 articles (46.25\%), the public health situations or events were only described and the author did not make any recommendations. For 16 articles $(20 \%)$, the author chooses not only to describe the medical reality of the period but also to assess the existing state of affairs in the domain and make recommendations for the future.

The analysis of article on the axis of "colloquial" or "scientific" language showed that the majority of articles had been written in a simple, direct language (69 articles - that is, $86.25 \%$ of the entire sample) and only in the case of 12 articles (13.75\%) the medical jargon was used.

Table 8. Type of language used in the article

\begin{tabular}{|l|c|c|}
\hline $\begin{array}{l}\text { Colloquial language (the information can be easily understood by } \\
\text { the average reader) }\end{array}$ & N & Percent (\%) \\
\hline $\begin{array}{l}\text { Expert language (the information can be understood with some } \\
\text { difficulty by the average reader) }\end{array}$ & 12 & 13.75 \\
\hline
\end{tabular}

Journalists' attitude towards the topics covered in articles was different from one magazine or review to another. On the basis of our sample, we could identify five major positions for the journalists and experts who authored articles enclosed in the analysis. The first attitude was the impersonal one, registered for 26 articles $(32.5 \%)$. In this case, the author did not express his or her position on the topic but only had transmitted clearly the information (mainly of a scientific type). The second type of attitude is that of a medical expert - the author of the article had presented her or his knowledge in the medical field and had made technical recommendations related to the article's topic. This attitude was recorded in the case of 16 articles (20\%). The third type of attitude refers to the positive assessment of the Romanian medical system, medical services or health-related facilities and it was recorded in the case of 15 articles (18.75\%). Fourth, the journalists' and experts' critical assessments of existing medical conditions and facilities in Romania were recorded in 12 articles (15\%). Finally, the fifth types of attitude was that of making recommendations referring either to the whole medical system, to 
various sub-systems or regarding the medical research and this was the case of 11 articles $(13.75 \%)$ we have analyzed.

\section{Discussions}

According to the existing literature (Gitlin, 1980; Reese, 1997), the paradigm of journalism can be seen as a model that governs the collection of information, manifested in practical journalism and focused on the evaluation criteria of journalistic potential and on the ways of their transmission to the public. The cornerstone of this model is objectivity (Reese, 1997, p. 424). The role of the media in this process is to make visible the limits of each definition of reality (Gitlin, 1980; Reese, 1997), the media reproducing a consistent ideology. As bearers of truth, journalists naturally oppose manipulation by sources or by their managers, which is quite likely to happen within the framework of their professional, having sufficient means available to achieve this thing. Accepting as a rule that the journalism is free from values, the media supports and emphasizes values, ideological frameworks, and rules set by the dominant elites. The process of drafting news serves well to hegemonic principles as generally editing decisions are made by the editors, who are supposed to be more experienced and have a broader view of the world; they also have extensive contacts with officials and elite sources, which influences them in the formation of the "vision" of the world (Reese, 1997). As literature recognizes (Rieffel, 1994), when an article or a piece of news appears in the media, only the journalist's idea to make a material or reflection or to report a material exists before the information provided by sources. After the idea, sources "are" virtually materials producers, they give the approach angle, they stress or not certain information, driving it erratically in public or simply sending "test balloons" through journalists. Given the role of the "map" of the sources in the production of articles and news and its relation to the journalists' professional imaginary, we can notice that in the case of Romanian printed media the number of sources related to medical system and public health not only was a small one but they have a different quality, since they were represented mainly by people connected to the domain - doctors, ministers, researchers, and professors at the faculty of medicine.

Some authors (Molotoch and Lester, 1997) have distinguished between three categories of events presented by the media: (1) routine events; (2) accidents; (3) scandals. Molotoch and Lester (1997) show that the existence of three types of events is an indicator of the centrality of organizational planning in the activities of media organizations. Also, the inclusion of an event in a certain class endorses organizations regarding the events codification made by journalists. In the case of our sample, the analysis had shown that the majority of events presented in Romanian reviews and magazines could be enclosed in the first type of event - the inter-war journalists and specialists had chosen to present routine events related to public health and medicine, and not mainly scandals and accidents.

Referring to the work of journalism, Jeffres (1986) have differentiated between objective standards of professional culture on the one hand and elements derived from the very specific events presented by the media. We considered that we could identify professional and organizational variables that were functional in Romanian media between 1918 and 1945. The most important of them was the fact that the experts of that period of time had been a "voice" in the public debate about health and medicine. 


\section{Conclusions}

We can conclude by noticing the fact that the image of public health in Romanian printed press for the period 1918-1945 was differently framed by the specialists and journalists as compared with present-day media. The reviews and magazines had published articles which had stressed the role of media as formal educators about the medical system through the use of citations from laws and official documents, extended coverage of medical discoveries, making recommendations about the future of the system and adopting an impersonal attitude towards the topics presented.

Thus, the Romanian authors of the articles enclosed in the sample published had put a greater stress on the quality of information regarding health and medicine, stressing the objectivity of the scientific evidence, using few images or photos, covering the topics on long articles (more than one page of the publication) and quoting experts from the domain with direct reference to the topics.

Conflict of interest. The author of this article does not have any conflict of interests.

\section{Bibliography}

1. Bărbulescu, C., 2010. Ţărani, boli și vindecători în perioada comunistă: Marturii orale, vol. II, Cluj-Napoca: Mega.

2. Bărbulescu, C., 2015. România Medicilor. Medici, țărani și igienă rurală în România de la 1860 până la 1910, București: Humanitas.

3. Baresch, B., Hsu, S., and Reese, S., 2012. Studies in news framing. In: S. Allan (Ed.) Routledge companion to news and journalism studies, New York, NY: Routledge, pp. 637647.

4. Beciu, C., 2011. Sociologia comunicării şi a spaţiului public: concepte, teme, analize. Iași, Polirom.

5. Chelcea, S., 2001. Metodologia cercetării sociologice: metode cantitative şi calitative. București: Editura Economică.

6. D'Angelo, P., 2002. News framing as a multiparadigmatic research program: A response to Entman. Journal of Communication, 52, pp. 870-888.

7. De Vreese, C. and Boomgaarden, H., 2003. Valenced news frames and public support for the EU. Communications, 28(4), pp. 361-381.

8. Entman, R.M. and Rojecki, A., 1993. Freezing out the public: Elite and media framing of the US anti-nuclear movement. Political Communication, 10, pp.155-173.

9. Ettema, J.S. and Peer, L., 1996. Good News from a Bad Neighborhood: Toward an Alternative to the Discourse of Urban Pathology. Journalism \& Mass Communication Quarterly, 73(4), pp.835-856.

10. Ferree, M.M., Gamson, W.A., Gerhards, J. and Rucht, D., 2002. Shaping abortion discourse: Democracy and the public sphere in Germany and the United States, Cambridge, England: Cambridge University Press.

11. Gamson, W.A. and Modigliani, A., 1989. Media Discourse and Public Opinion on Nuclear Power: A Constructionist Approach. American Journal of Sociology, 95(1), pp.1-37.

12. Gitlin, T., 1980. The whole world is watching. Berkeley: The University of California Press.

13. Iyengar, S., 1990. Framing responsibility for political issues: The case of poverty. Political Behaviour, 12(1), pp.19-40.

14. Jeffres, L., 1986. Mass-media, processes and effects. Illinois: Waveland Press Inc.

15. McCombs, M., 2004. Setting the agenda. Cambridge: Polity Press. 
16. Molotoch, H. and Lester, M., 1997. News as Purposive Behaviour, On the Strategic Use of Routine Events, Accidents and Scandals. In: D. Berkowitz (Ed.). Social Meaning of News, Sage Publications Inc., pp. 200-205.

17. Reese, S., 1997. The News Paradigm and the Ideology of Objectivity. In: D. Berkowitz (Ed.), Social Meaning of News. Thousand Oaks, CA: Sage Publications Inc., pp. 420-437.

18. Rieffel, R., 1994. L'elite des journalistes. Paris: PUF.

19. Scheufele, B., 2004. Framing-effects approach: A theoretical and methodological critique. Communications, 29(4), pp. 401-428.

20. Semetko, H.A. and Valkenburg, P.M., 2000. Framing European politics: A content analysis of press and television news. Journal of Communication, 50(2), pp. 93-109.

21. Setlacec, D., 1998. Medicină Românească - Medicină Europeană 1918-1940, București: Humanitas.

22. Shah, D.V., Boyle, M.P., Schmierbach, M., Keum, H. and Armstrong, C.L., 2010. Specificity, Complexity, and Validity: Rescuing Experimental Research on Framing Effects. In: P. D'Angelo and J.A. Kuypers (Eds.) Doing News Frame Analysis. New York: Routledge, pp. 215-232.

23. *** Albina. ["The Bee"] Revistă enciclopedică populară, 1918-1945. [periodical]. Bucharest: The Bucharest Digital Library. [online] Available at: $<\mathrm{http}: / / w w w . d i g i b u c . r o /$ cautare [Accessed 15 December 2018].

24. *** Boabe de grâu ["Grains of wheat"], 1918-1945. [periodical]. Bucharest: The Bucharest Digital Library. [online] Available at: <http://www.digibuc.ro/cautare $>$. [Accessed 15 December 2018].

25. *** Epoca [“The epoch/era"], 1918-1945. [periodical]. Bucharest: The Bucharest Digital Library. [online] Available at: <http://www.digibuc.ro/cautare>. [Accessed 16 December 2018].

26. *** Medicina populară ["People's Medicine"], 1918-1945. [periodical]. Bucharest: The Bucharest Digital Library. [online] Available at: <http://www.digibuc.ro/cautare $>$. [Accessed 15 December 2018].

27. *** Memoriile secţiunii ştiintifice - Secţiunea Medicală ["The memories of the scientific section- Medical section"], 1918-1945. [periodical]. Bucharest: The Bucharest Digital Library. [online] Available at: <http://www.digibuc.ro/cautare $>$. [Accessed 14 December 2018].

28. *** Monitorul Oficial [“The Official Monitor"], 1918-1945. [periodical]. Bucharest: The Bucharest Digital Library. [online] Available at: <http://www.digibuc.ro/cautare>. [Accessed 15 December 2018].

29. *** Pagini populare ["Popular pages"], 1918-1945. [periodical]. Bucharest: The Bucharest Digital Library. [online] Available at: <http://www.digibuc.ro/cautare>. [Accessed 16 December 2018].

30. *** Sociologie românească ["Romanian Sociology"], 1918-1945. [periodical]. Bucharest: The Bucharest Digital Library. [online] Available at: <http://www.digibuc.ro/cautare>. [Accessed 17 December 2018]. 